\title{
Implementation of Back At work After Surgery \\ (BAAS): a feasibility study of an integrated pathway for improved return to work after knee arthroplasty
}

Daniel Otto Strijbos ( $\nabla$ d.o.strijbos@amsterdamumc.nl )

Amsterdam Universitair Medische Centra https://orcid.org/0000-0002-8286-7788

Geert van der Sluis

Hanze University of Applied Sciences: Hanzehogeschool Groningen

Tim A.E.J. Boymans

Maastricht University Hospital: Maastricht Universitair Medisch Centrum+

Stephan de Groot

Elabo B.V.

Simon Klomp

a.s.r. insurences

\section{Carolien M. Kooijman}

Hospital Nij Smellinghe: Ziekenhuis Nij Smellinghe

Michiel F. Reneman

University Medical Centre Groningen: Universitair Medisch Centrum Groningen

Paul P.F.M. Kuijer

Amsterdam UMC - Locatie AMC: Amsterdam UMC Locatie AMC

\section{Research Article}

Keywords: Knee arthroplasty, return to work, health plan implementation, feasibility studies, occupational health service, orthopedics, physical therapy modalities

Posted Date: March 9th, 2022

DOI: https://doi.org/10.21203/rs.3.rs-1361542/v2

License: (c) (i) This work is licensed under a Creative Commons Attribution 4.0 International License. Read Full License

Version of Record: A version of this preprint was published at Musculoskeletal Care on May 4th, 2022. See the published version at https://doi.org/10.1002/msc.1633. 


\section{Abstract}

Purpose: Optimizing return to work after knee arthroplasty is becoming more important because of the growing incidence of KA among workers and poor return to work outcomes. The purpose of this study is to investigate the feasibility of Back At work After Surgery (BAAS): an integrated clinical pathway for return to work after knee arthroplasty.

Method: Working patients who received unicompartmental knee arthroplasty (UKA) or total knee arthroplasty (TKA) between January 2021 and November 2021, younger than 65 years and motivated to return to work were eligible to participate. Feasibility was investigated on five domains: reach, dose delivered, dose received, fidelity and patients' attitudes. These outcomes were obtained by a patientreported questionnaire and an interview with the occupational case manager and medical case manager.

Results: Of the eligible 29 patients, eleven were willing to participate (response rate $38 \%$; due to travel distance to and from the hospital). The dose delivered was between 91 and 100\%, except information given about return to work from the orthopedic surgeon which was $18 \%$. The dose received was $100 \%$. For fidelity, case managers reported nine shortcomings for which five solutions were mentioned. In terms of patients' attitude, all patients were satisfied and one patient mentioned an improvement.

Conclusions: In terms of reach, participation was low: only $29 \%$. The BAAS clinical pathway seems feasible based on dose delivered, dose received, fidelity and patient attitudes. The next step is to assess the effectiveness of the BAAS clinical pathway for return to work.

\section{Introduction}

For patients, return to work (RTW) after knee arthroplasty (KA) is becoming more important due to the growing incidence of KA, especially among patients of working age (Ackerman et al., 2019; Otten et al., 2010; Kurtz et al., 2007; Culliford et al., 2015; Price et al., 2018). Although pain relief and knee function are satisfactory after KA, RTW among patients is relatively low, about $50 \%$ within six months after KA (Hylkema et al., 2021), and 68\% do not return to work after two years (Kievit et al., 2014).

A closer collaboration between professionals in surgical care (e.g., orthopedic surgeons, physical therapists) and occupational care (e.g., occupational physicians) might improve RTW (Hylkema et al., 2022). Unfortunately, proven effective interventions are not available yet for these patients (Kuijer et al., 2018; Coenen et al., 2020).

We developed Back At work After Surgery (BAAS): an integrated clinical pathway for improved RTW after KA. This newly designed pathway follows the recommendations of the clinical guideline to optimize work participation by timely combination of medical and occupational care (Daley et al., 2021). 
To the best of our knowledge, this is the first initiative to evaluate the feasibility of work-directed care among patients receiving $\mathrm{KA}$.

\section{Method}

\section{Study design and setting}

A single center study was performed with permission of the medical ethical committee of Nij Smellinghe hospital (reference ID: 17050/JvE/AB) and described using the STROBE statement (Vandenbroucke et al., 2007). KA was performed by three of the five orthopedic surgeons in this regional hospital.

\section{Participants}

The following are the patient eligibility criteria: 1) being scheduled for UKA or TKA due to knee osteoarthritis between January and November 2021;2) having paid work; and 3) willing to fully RTW. Exclusion criteria were 1) receiving another surgical intervention within one year; 2) having a major mental disorder; 3) insufficiently fluency in Dutch; or 4) not willing to receive physical therapy in Nij Smellinghe hospital. Eligible patients were informed by telephone about the study and received an information letter, informed consent and an infographic of the BAAS clinical pathway at home (Appendix I). Patients were called one week later to answer any additional questions about the study and were asked if they wanted to participate by signing the informed consent.

\section{Intervention: the BAAS clinical pathway}

The orthopedic surgeon preoperatively provided information about time to RTW and prognostic factors for delayed RTW (Figure 1) (van Leemput et al., 2021; Kuijer et al., 2016) and recommended that the patient consult the occupational physician before surgery. Next, the patient was referred to the occupational case manager (OCM, occupational assessor) to compile a report of beneficial and limiting factors regarding RTW after KA.

Next, the patient was referred to a MCM for a preoperative examination to address the patient's expectations and set a benchmark for physical functioning (Krysa et al., 2022). The patient also filled in questionnaires and performed three tests to evaluate functioning (Table 1 and Figure 1) (Kievit 2014, Bouwmans 2015, Kregel 2016, Roos 1998, Jans et al., 2011; Enright et al., 2003; Csuka et al., 1985). Moreover, the patient was given information about the perioperative care and received an accelerometer (PAM 2.0) and access to the Atris platform to assess the movement data (Peercode B.V.) (Slootmakers, 2009). A week later, the CCM called the patient to discuss the physical activity assessed by the accelerometer and gave advice regarding the preferred physical preparation, like practicing to walk with an aid and trying to adhere to the World Health Organization's activity guideline (Larsen et al., 2022; WHO 
2020). The findings of the preoperative examination were used as baseline measurements for goalsetting in the postoperative rehabilitation and, not as an outcome for this feasibility study. During the hospitalization, the patients received care according to the KA fast-track principles (Altman et al., 2019).

Postoperatively, the patient received physical therapy according to the Royal Dutch Society for Physiotherapy guideline, starting sessions twice a week (van Doormaal et al., 2020). The first sessions were at the patient's home to train activities of daily living, such as climbing stairs. These sessions started 24-48 hours after discharge from the hospital until about week 4. Next, physical therapy was once or twice a week, depending on the patient's needs, at the outpatient facility within Nij Smellinghe hospital. Goals shifted from activities of daily living to activities necessary for RTW. Goals were formally monitored every six weeks by Goal Attainment Scaling (GAS, Figure 1). Progress was evaluated by questionnaires (WORQ, KOOS, and CSI) and functional tests (DEMMI, FTSST and 6MWT) every six weeks and accelerometry on a weekly basis (Figure 1). Stop criteria were full RTW with a maximum follow-up of two years. A multidisciplinary consult (MDC) was held the fourth or fifth week after KA. The patient, the physical therapist, MCM, OCM and occupational physician were invited and the progress in recovery was discussed including the RTW plan according to the Dutch Gatekeeper Improvement Act (Figure 1). If the patient had a job which he likely could not return to (e.g., because of high knee demands), the possibility of work adaptions or even the topic of finding a less strenuous job were discussed (Figure 1). The MDC was continued if indicated. If, after three months, a delayed recovery was seen based on patient's experience, the measured data and the expert opinions of MCM, OCM and occupational physician, the patient was referred to a multidisciplinary rehabilitation assessment (Figure 1). Here, the patient was examined by a rehabilitation physician, occupational specialist, physical therapist and psychologist to assess barriers for delayed RTW and the patient's eligibility for an interdisciplinary vocational rehabilitation program. If eligible, the patient then received this program (Beemster et al., 2021).

Table 1: Questionnaires and functional tests used to measure recovery 


\section{Questionnaires}

Work,

Osteoarthritis and scale

Joint-Replacement questions

Questionnaire

(WORQ)

Knee Injury and

Osteoarthritis

Outcome Score

(KOOS)

Central

Sensitization

Inventory (CSI)

iMTA Productivity

Cost

Questionnaire

(iPCQ)

Thirteen 0-4

scale

questions

regarding

work.

Twenty-five 0-

4 scale

questions

Eleven

questions

regarding

health and

work
0-100 scale total score in five domains

(KA related symptoms, pain, activities, sport participation and quality of life)
More disability in

work-related and knee

demanding activities

Less experienced

disabilities in given

domains.
Less chance of developing central sensitization related disabilities.

\section{Functioning testing}

de Morton

Mobility Index

(DEMMI)

Five Time Sit to

Stand Test

(FTSST)

6-minute walk

Time in

seconds
Time in seconds

seconds
Less able to perform mobility skills

Less able to perform mobility skills

Less able to perform mobility skills 


\section{Feasibility outcomes}

To assess feasibility, five outcomes were analyzed: reach, dose received, dose delivered, fidelity and patient attitudes (Linnan et al., 2002). To assess reach, the degree of participation by the patients, occupational physicians and employers was analyzed. To assess dose delivered, the proportion of the intervention that was delivered to the participants by orthopedic surgeons, OCM and MCM was analyzed. For dose received, exposure and usage of the intervention components was measured using a selfreported questionnaire filled in by the patients after they fully returned to work or six months after surgery (Appendix II) (Bowen et al., 2009). To assess fidelity, an interview was held with the MCM and OCM by a third author (PK). For each patient, it was discussed whether the intended care was given as planned. Lastly, patient attitudes were measured using a self-reported questionnaire about the received care (Appendix II).

\section{Sample size}

We aimed to include twenty consecutive patients. This number was based on expectations that these 20 patients secure enough variability to determine whether the BAAS clinical pathway is feasible for all eligible patients with KA. To assess variability, prognostic factors for RTW of each patient were described, including preoperative sick-leave duration, body mass index (BMI) and physical demands of the job (Kuijer et al., 2016).

\section{Statistical methods}

Patient characteristics were described with median and interquartile range (IQR). Primary outcomes (reach, dose delivered, dose received, fidelity and patient attitudes) were described. Data were analyzed using SPSS version 26.1.

\section{Results}

\section{Participants}

In the study period, 249 patients received a TKA or UKA and 80 were younger than 65 years. Fifty-one patients did not meet the inclusion or exclusion criteria, and 29 patients were asked to participate. Eleven agreed to participate. The remaining 18 patients were not willing to participate due to long travel distance to the hospital (Figure 2). 
Of the eleven participants, the median age was 59 years, seven were female, and eight received TKA (Table 2). All patients fully returned to work within the first year, on average after 14 weeks after KA. One patient switched to another employer and started in a less demanding job. One patient was seen for a multidisciplinary rehabilitation assessment.

[Tables 2-4 are in the supplementary files section.]

\section{Feasibility}

All patients completed the feasibility questionnaire (Table 3 ). In terms of reach, $38 \%$ of the invited patients decided to participate. Regarding dose delivered, only two orthopedic surgeons (18\%) informed patients about RTW. All patients received the intended care. One patient did not have contact with an occupational physician and did not have contact with the employer about RTW. This was due to the fact that this patient was self-employed.

In terms of fidelity, seven shortcomings in care were reported. For these shortcomings in care, OCM and MCM mentioned five possible improvements (Table 4).

Finally, all patients mentioned being satisfied with the BAAS clinical pathway. One patient was dissatisfied that the orthopedic surgeon had not mentioned the high risk of no RTW due to his high kneedemanding work.

\section{Discussion}

Key results

The BAAS clinical pathway appeared to be feasible in terms of dose delivered, dose received, fidelity and patients' attitudes. The reach appeared low in comparison to other feasibility studies among patients receiving orthopedic care reporting data about 63\%, 59\% and 30\% (Kumar et al., 2020; Resnick et al., 2016; Vrenceanu et al., 2019). Our reach was $38 \%$. This low reach was mainly due to the long travel distance to the hospital for physical therapy. 
To increase reach, we suggest giving the physical therapy care from primary care physical therapists nearby the patient's home. This is also in line with the right care in the right place (https://english.zorginstituutnederland.nl/). To increase the dose delivered, we advise training the orthopedic surgeons to inform patients better about RTW and relevant prognostic factors, in line with recent studies (Pahlplatz et al., 2021; van Leemput et al., 2021; Kuijer et al., 2016). Future studies should investigate whether these measures indeed improved the feasibility.

\section{Generalizability}

The BAAS clinical pathway seems feasible within the Dutch social security and care systems. Further research is needed to assess the effectiveness on RTW. This study will be performed with a second hospital in the Netherlands to overcome any bias introduced by the clinical involvement of the primary researcher. In comparison to other studies among working-age patients with $\mathrm{KA}$, the present patient characteristics were similar in terms of age, sex and educational level (Hylkema et al., 2021; van Leemput et al., 2021). An important prognostic factor for RTW for patients with KA are the physical job demands (van Leemput et al., 2021). Despite the low number of participants, the job demands ranged from low knee-demanding desk work to high knee-demanding work as a mechanic in which RTW appeared not possible. Lastly, the primary investigator fulfilled the roll of MCM. Thus, the expertise regarding RTW after KA might be higher than average. Therefore, future MCMs in other hospitals and clinics should be trained before implementing the BAAS clinical pathway. For the OCM, external validity is covered by using a service available nationwide due to the Dutch Gatekeeper Improvement Act.

\section{Strengths and limitations}

The BAAS clinical pathway is, to the best of our knowledge, the first clinical pathway to focus on RTW as the main outcome after KA (Kuijer et al., 2018; Coenen et al., 2020). Unfortunately, no data were available on the feasibility or effectiveness of the Occupational advice for Patients undergoing Arthroplasty of the Lower limb (OPAL study) (Baker et al., 2020). Important similarities between OPAL and our pathway are an interdisciplinary approach and patient-centered care. This is in line with the clinical guidance of Daley and colleagues on work participation (Daley et al., 2021). They advised a timely combination of medical rehabilitation and occupational RTW care, including the use of self-reported and performance-based measures. In the Netherlands, another intervention was evaluated for working-age patients with KA, aiming at improved RTW, namely the ACTIVE trial (https://www.trialregister.nl/trial/8525) (Straat et al., 2020). This intervention combines referral to a case manager in the hospital or clinic and rehabilitation with personalized goals and eHealth. In contrast with the BAAS clinical pathway, the case manager in the ACTIVE trial does not actively enhance cooperation or communication between patient, employer, OCM and the other healthcare professionals. 
This study had two important limitations. First, the number of participating patients did not reach 20 , but only 11. This was mainly due to restrictions in number of KA in the hospital, related to the SARS-COVID19 pandemic. Secondly, the willingness of primary physical therapy settings to participate in the present BAAS pathway instead of physical therapy given from the hospital is not investigated. Future studies should show whether this is feasible.

\section{Declarations}

\section{Funding}

This study was partly funded by the Dutch insurance company a.s.r.

\section{References}

Ackerman, I. N., Bohensky, M. A., Zomer, E., Tacey, M., Gorelik, A., Brand, C. A., \& de Steiger, R. (2019). The projected burden of primary total knee and hip replacement for osteoarthritis in Australia to the year 2030. BMC musculoskeletal disorders, 20(1), 90. https://doi.org/10.1186/s12891-019-2411-9

Otten, R., van Roermund, P. M., \& Picavet, H. S. (2010). Trends in aantallen knie- en heupartroplastieken: de vraag naar knie- en heupprotheses blijft voorlopig toenemen [Trends in the number of knee and hip arthroplasties: considerably more knee and hip prostheses due to osteoarthritis in 2030]. Nederlands tijdschrift voor geneeskunde, 154, A1534.

Kurtz, S., Ong, K., Lau, E., Mowat, F., \& Halpern, M. (2007). Projections of primary and revision hip and knee arthroplasty in the United States from 2005 to 2030. The Journal of bone and joint surgery. American volume, 89(4), 780-785. https://doi.org/10.2106/JBJS.F.00222

Culliford, D., Maskell, J., Judge, A., Cooper, C., Prieto-Alhambra, D., Arden, N. K., \& COASt Study Group (2015). Future projections of total hip and knee arthroplasty in the UK: results from the UK Clinical Practice Research Datalink. Osteoarthritis and cartilage, 23(4), 594-600.

https://doi.org/10.1016/j.joca.2014.12.022

Price, A. J., Alvand, A., Troelsen, A., Katz, J. N., Hooper, G., Gray, A., Carr, A., \& Beard, D. (2018). Knee replacement. Lancet (London, England), 392(10158), 1672-1682. https://doi.org/10.1016/S01406736(18)32344-4

Hylkema, T. H., Stevens, M., van Beveren, J., Rijk, P. C., Brouwer, R. W., Bulstra, S. K., Kuijer, P., \& Brouwer, S. (2021). Recovery Courses of Patients Who Return to Work by 3, 6 or 12 Months After Total Knee Arthroplasty. Journal of occupational rehabilitation, 31(3), 627-637. https://doi.org/10.1007/s10926021-09959-6

Kievit, A. J., van Geenen, R. C., Kuijer, P. P., Pahlplatz, T. M., Blankevoort, L., \& Schafroth, M. U. (2014). Total knee arthroplasty and the unforeseen impact on return to work: a cross-sectional multicenter survey. The 
Journal of arthroplasty, 29(6), 1163-1168. https://doi.org/10.1016/j.arth.2014.01.004

Hylkema, T. H., Brouwer, S., Stewart, R. E., van Beveren, J., Rijk, P. C., Brouwer, R. W., Bulstra, S. K., Kuijer, P., \& Stevens, M. (2022). Two-year recovery courses of physical and mental impairments, activity limitations, and participation restrictions after total knee arthroplasty among working-age patients. Disability and rehabilitation, 44(2), 291-300. https://doi.org/10.1080/09638288.2020.1766583

Pahlplatz, T., Schafroth, M. U., Krijger, C., Hylkema, T. H., van Dijk, C. N., Frings-Dresen, M., \& Kuijer, P. (2021). Beneficial and limiting factors in return to work after primary total knee replacement: Patients' perspective. Work (Reading, Mass.), 69(3), 895-902. https://doi.org/10.3233/WOR-213522

Kuijer, P., van Haeren, M. M., Daams, J. G., \& Frings-Dresen, M. (2018). Better return to work and sports after knee arthroplasty rehabilitation?. Occupational medicine (Oxford, England), 68(9), 626-630. https://doi.org/10.1093/occmed/kqy131

Coenen, P., Hulsegge, G., Daams, J. G., van Geenen, R. C., Kerkhoffs, G. M., van Tulder, M. W., Huirne, J. A., Anema, J. R., \& Kuijer, P. P. (2020). Integrated care programmes for sport and work participation, performance of physical activities and quality of life among orthopaedic surgery patients: a systematic review with meta-analysis. BMJ open sport \& exercise medicine, 6(1), e000664.

https://doi.org/10.1136/bmjsem-2019-000664

Daley, D., Payne, L. P., Galper, J., Cheung, A., Deal, L., Despres, M., Garcia, J. D., Kistner, F., Mackenzie, N., Perry, T., Richards, C., \& Escorpizo, R. (2021). Clinical Guidance to Optimize Work Participation After Injury or Illness: The Role of Physical Therapists. The Journal of orthopaedic and sports physical therapy, 51(8), CPG1-CPG102. https://doi.org/10.2519/jospt.2021.0303

Hoorntje, A., Waterval-Witjes, S., Koenraadt, K., Kuijer, P., Blankevoort, L., Kerkhoffs, G., \& van Geenen, R. (2020). Goal Attainment Scaling Rehabilitation Improves Satisfaction with Work Activities for Younger Working Patients After Knee Arthroplasty: Results from the Randomized Controlled ACTION Trial. The Journal of bone and joint surgery. American volume, 102(16), 1445-1453.

https://doi.org/10.2106/JBJS.19.01471

Larsen, R. T., Wagner, V., Korfitsen, C. B., Keller, C., Juhl, C. B., Langberg, H., \& Christensen, J. (2022). Effectiveness of physical activity monitors in adults: systematic review and meta-analysis. BMJ (Clinical research ed.), 376, e068047. https://doi.org/10.1136/bmj-2021-068047

Vandenbroucke, J. P., von Elm, E., Altman, D. G., Gøtzsche, P. C., Mulrow, C. D., Pocock, S. J., Poole, C., Schlesselman, J. J., Egger, M., \& STROBE Initiative (2007). Strengthening the Reporting of Observational Studies in Epidemiology (STROBE): explanation and elaboration. PLoS medicine, 4(10), e297. https://doi.org/10.1371/journal.pmed.0040297

Van Leemput, D., Neirynck, J., Berger, P., \& Vandenneucker, H. (2021). Return to Work after Primary Total Knee Arthroplasty under the Age of 65 Years: A Systematic Review. The journal of knee surgery, 
10.1055/s-0040-1722626. Advance online publication. https://doi.org/10.1055/s-0040-1722626

Kuijer, P. P., Kievit, A. J., Pahlplatz, T. M., Hooiveld, T., Hoozemans, M. J., Blankevoort, L., Schafroth, M. U., van Geenen, R. C., \& Frings-Dresen, M. H. (2016). Which patients do not return to work after total knee arthroplasty?. Rheumatology international, 36(9), 1249-1254. https://doi.org/10.1007/s00296-016-35125

Krysa, J. A., Ho, C., O'Connell, P., \& Pohar Manhas, K. (2022). Clinical practice recommendations for prehabilitation and post-operative rehabilitation for arthroplasty: A scoping review. Musculoskeletal care, 10.1002/msc.1621. Advance online publication. https://doi.org/10.1002/msc.1621

Kievit, A. J., Kuijer, P. P., Kievit, R. A., Sierevelt, I. N., Blankevoort, L., \& Frings-Dresen, M. H. (2014). A reliable, valid and responsive questionnaire to score the impact of knee complaints on work following total knee arthroplasty: the WORQ. The Journal of arthroplasty, 29(6), 1169-1175.e2.

https://doi.org/10.1016/j.arth.2014.01.016

Bouwmans, C., Krol, M., Severens, H., Koopmanschap, M., Brouwer, W., \& Hakkaart-van Roijen, L. (2015). The iMTA Productivity Cost Questionnaire: A Standardized Instrument for Measuring and Valuing Health-Related Productivity Losses. Value in health : the journal of the International Society for Pharmacoeconomics and Outcomes Research, 18(6), 753-758.

https://doi.org/10.1016/j.jval.2015.05.009

Kregel, J., Vuijk, P. J., Descheemaeker, F., Keizer, D., van der Noord, R., Nijs, J., Cagnie, B., Meeus, M., \& van Wilgen, P. (2016). The Dutch Central Sensitization Inventory (CSI): Factor Analysis, Discriminative Power, and Test-Retest Reliability. The Clinical journal of pain, 32(7), 624-630.

https://doi.org/10.1097/AJP.0000000000000306

Roos, E. M., Roos, H. P., Lohmander, L. S., Ekdahl, C., \& Beynnon, B. D. (1998). Knee Injury and Osteoarthritis Outcome Score (KOOS)-development of a self-administered outcome measure. The Journal of orthopaedic and sports physical therapy, 28(2), 88-96.

https://doi.org/10.2519/jospt.1998.28.2.88

Jans, M. P., Slootweg, V. C., Boot, C. R., de Morton, N. A., van der Sluis, G., \& van Meeteren, N. L. (2011). Reproducibility and validity of the Dutch translation of the de Morton Mobility Index (DEMMI) used by physiotherapists in older patients with knee or hip osteoarthritis. Archives of physical medicine and rehabilitation, 92(11), 1892-1899. https://doi.org/10.1016/j.apmr.2011.05.011

Enright, P. L., McBurnie, M. A., Bittner, V., Tracy, R. P., McNamara, R., Arnold, A., Newman, A. B., \& Cardiovascular Health Study (2003). The 6-min walk test: a quick measure of functional status in elderly adults. Chest, 123(2), 387-398. https://doi.org/10.1378/chest.123.2.387

Csuka, M., \& McCarty, D. J. (1985). Simple method for measurement of lower extremity muscle strength. The American journal of medicine, 78(1), 77-81. https:// doi.org/10.1016/0002-9343(85)90465-6. 
Slootmaker, S. M., Chin A Paw, M. J., Schuit, A. J., van Mechelen, W., \& Koppes, L. L. (2009). Concurrent validity of the PAM accelerometer relative to the MTI Actigraph using oxygen consumption as a reference. Scandinavian journal of medicine \& science in sports, 19(1), 36-43. https://doi.org/10.1111/j.16000838.2007.00740.x

WHO Guidelines on Physical Activity and Sedentary Behaviour. Geneva: World Health Organization; 2020.

Altman, A. D., Helpman, L., McGee, J., Samouëlian, V., Auclair, M. H., Brar, H., Nelson, G. S., \& Society of Gynecologic Oncology of Canada's Communities of Practice in ERAS and Venous Thromboembolism (2019). Enhanced recovery after surgery: implementing a new standard of surgical care. CMAJ : Canadian Medical Association journal = journal de l'Association medicale canadienne, 191(17), E469E475. https://doi.org/10.1503/cmaj.180635

Zimmer Biomet. Oxford partial knee microplasty instrumentation surgical technique. https://www.zimmerbiomet.com/content/dam/zimmer-biomet/medical-professionals/000-surgicaltechniques/knee/oxford-partial-knee-microplasty-instrumentation-surgical-technique.pdf. Accessed 12022

MatOrtho. Medial Rotation Knee ${ }^{\mathrm{TM}}$. https://bdhmedical.nl/wpcontent/uploads/2018/06/MO_MRK_OT_ANTERIOR_ML_300_136_L_iss4_GLOBAL.pdf. Accessed 1-22022

Elings, J., Zoethout, S., Ten Klooster, P. M., van der Sluis, G., van Gaalen, S. M., van Meeteren, N., \& Hoogeboom, T. J. (2019). Advocacy for use of the modified lowa Level of Assistance Scale for clinical use in patients after hip replacement: an observational study. Physiotherapy, 105(1), 108-113. https://doi.org/10.1016/j.physio.2018.06.002

van Doormaal, M., Meerhoff, G. A., Vliet Vlieland, T., \& Peter, W. F. (2020). A clinical practice guideline for physical therapy in patients with hip or knee osteoarthritis. Musculoskeletal care, 18(4), 575-595. https://doi.org/10.1002/msc.1492

Beemster, T. T., van Bennekom, C., van Velzen, J. M., Frings-Dresen, M., \& Reneman, M. F. (2021). Vocational Rehabilitation with or without Work Module for Patients with Chronic Musculoskeletal Pain and Sick Leave from Work: Longitudinal Impact on Work Participation. Journal of occupational rehabilitation, 31(1), 72-83. https://doi.org/10.1007/s10926-020-09893-z

Linnan, L., and Steckler, A. (2002). Process Evaluation for Public Health Interventions and Research: An Overview. Process Eval. Public Heal. Interv. Res., pp. 1-23.

Bowen, D. J., Kreuter, M., Spring, B., Cofta-Woerpel, L., Linnan, L., Weiner, D., Bakken, S., Kaplan, C. P., Squiers, L., Fabrizio, C., \& Fernandez, M. (2009). How we design feasibility studies. American journal of preventive medicine, 36(5), 452-457. https://doi.org/10.1016/j.amepre.2009.02.002 
Kumar, S., Kumar, A., Kumar, M., Kumar, A., Arora, R., \& Sehrawat, R. (2020). Feasibility of telemedicine in maintaining follow-up of orthopaedic patients and their satisfaction: A preliminary study. Journal of clinical orthopaedics and trauma, 11(Suppl 5), S704-S710. https://doi.org/10.1016/j.jcot.2020.07.026

Resnick, B., Wells, C., Galik, E., Holtzman, L., Zhu, S., Gamertsfelder, E., Laidlow, T., \& Boltz, M. (2016). Feasibility and Efficacy of Function-Focused Care for Orthopedic Trauma Patients. Journal of trauma nursing : the official journal of the Society of Trauma Nurses, 23(3), 144-155.

https://doi.org/10.1097/JTN.0000000000000203

Vranceanu, A. M., Jacobs, C., Lin, A., Greenberg, J., Funes, C. J., Harris, M. B., Heng, M. M., Macklin, E. A., \& Ring, D. (2019). Results of a feasibility randomized controlled trial (RCT) of the Toolkit for Optimal Recovery (TOR): a live video program to prevent chronic pain in at-risk adults with orthopedic injuries. Pilot and feasibility studies, 5, 30. https://doi.org/10.1186/s40814-019-0416-7

Baker, P., Coole, C., Drummond, A., Khan, S., McDaid, C., Hewitt, C., Kottam, L., Ronaldson, S., Coleman, E., McDonald, D. A., Nouri, F., Narayanasamy, M., McNamara, I., Fitch, J., Thomson, L., Richardson, G., \& Rangan, A. (2020). Occupational advice to help people return to work following lower limb arthroplasty: the OPAL intervention mapping study. Health technology assessment (Winchester, England), 24(45), 1408. https://doi.org/10.3310/hta24450

Straat, A. C., Coenen, P., Smit, D., Hulsegge, G., Bouwsma, E., Huirne, J., van Geenen, R. C., Janssen, R., Boymans, T., Kerkhoffs, G., Anema, J. R., \& Kuijer, P. (2020). Development of a Personalized m/eHealth Algorithm for the Resumption of Activities of Daily Life Including Work and Sport after Total and Unicompartmental Knee Arthroplasty: A Multidisciplinary Delphi Study. International journal of environmental research and public health, 17(14), 4952. https://doi.org/10.3390/ijerph17144952.

\section{Tables}

Tables 2-4 are in the supplementary files section.

\section{Figures}




\section{Preoperative phase}

- Advice from orthopedic surgeon regarding return to work after surgery

- Advice given to patient to contact OP

- Compiling report of beneficial and limiting factors for RTW

- Accelerometer (until full RTW)

- Preoperative examination including questionnaires WORQ / KOOS / CSI / $\mathrm{iPCQ} /$ and performance-based tests DEMMI / FTSST and 6MWT

\section{Hospitalization}

- Usual care

\section{Postoperative phase}

- Goal Attainment Scaling

- Health surveillance, including WORQ/KOOS/ CSI / DEMMI / FTSST and 6MWT

- Multidisciplinary consult at 4 or 5 weeks and at 3 months postoperative

- Multidisciplinary rehabilitation and/or if necessary advise and support is given to find possibilities of work adaption or a less strenuous job in line with the Dutch Gatekeeper Law.

Figure I: the Back At work After Surgery (BAAS) clinical pathway.

Abbreviations: $6 M W T=6$-minute walk test, $C R T=$ Chair Rise Time, CSI: Central Sensitization Inventory, DEMMI $=$ de Morton Mobility Index, FTSST: Five Time Sit to Stand, $i P C Q=i M T A$ Productivity Cost Questionnaire, KOOS = Knee Osteoarthritis Outcome Score, $O P=$ occupational physician, $R T W=$ return to work, WORQ $=$ Work, Osteoarthritis and Joint-Replacement Questionnaire.

\section{Figure 1}

See image above for figure legend 
249 patients we nt for UKA or TKA

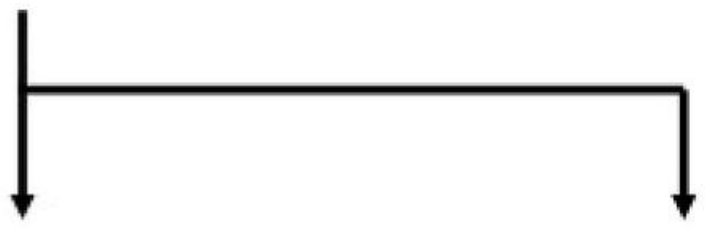

80 patients age of 65 or lower

169 patients age over 65
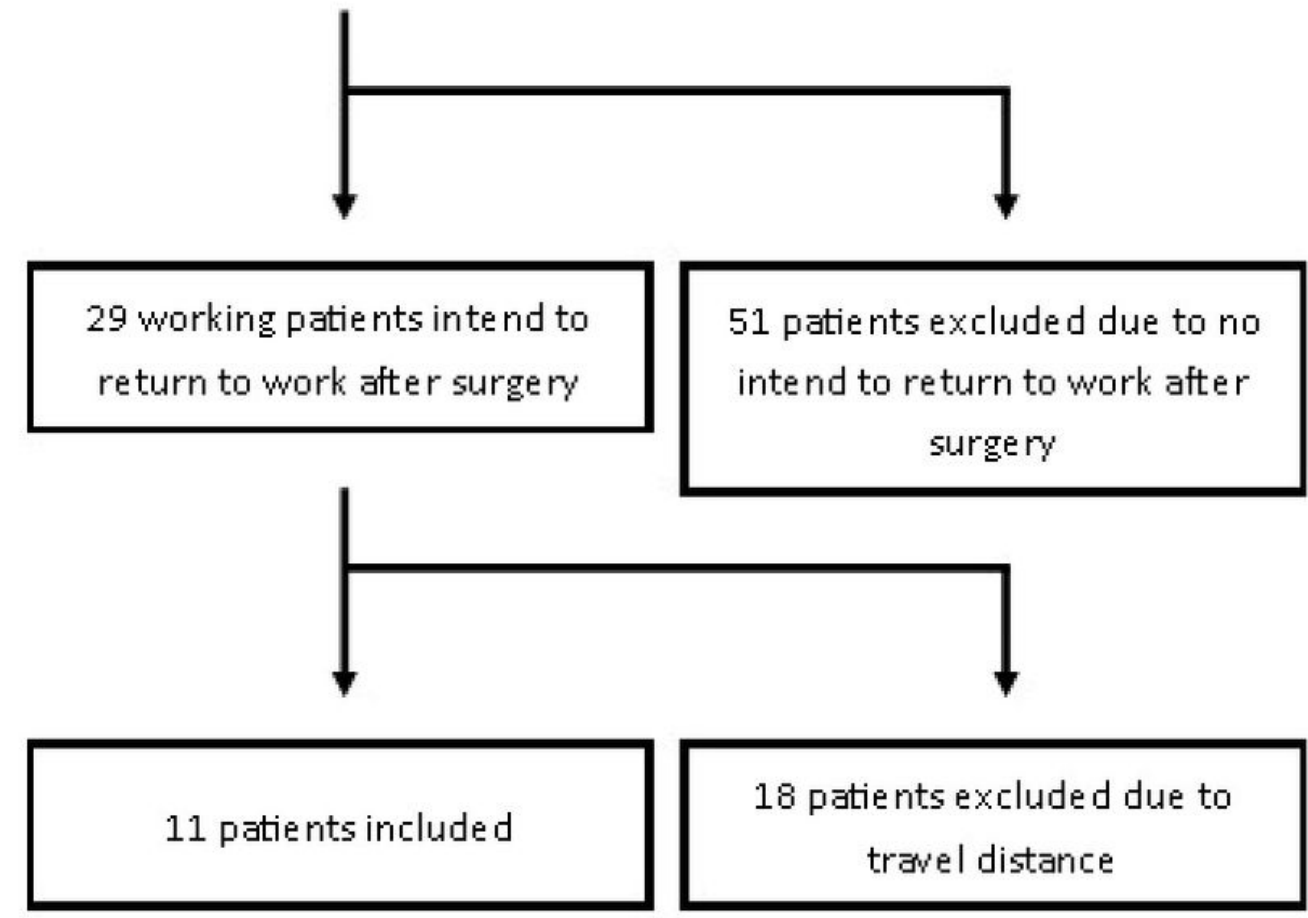

Figure 2: flowchart of in and exclusion. TKA = total knee arthroplasty, UKA = unicompartmental knee arthroplasty

Figure 2

See image above for figure legend

\section{Supplementary Files}

This is a list of supplementary files associated with this preprint. Click to download.

- Appendixl.docx

- Appendixll.docx 
- Tables24.docx

Page 16/16 